FORMATION Formation emploi

Revue française de sciences sociales

120 | Octobre-Décembre 2012

Parcours de formation : la recomposition des ségrégations

\title{
Mieux identifier les ségrégations, étape clé pour plus d'égalité
}

Jean-Frédéric Vergnies

\section{(2) OpenEdition}

Journals

Édition électronique

URL : http://journals.openedition.org/formationemploi/3776

DOI : $10.4000 /$ formationemploi.3776

ISSN : 2107-0946

Éditeur

La Documentation française

Édition imprimée

Date de publication : 31 octobre 2012

Pagination : 3-4

ISSN : 0759-6340

Référence électronique

Jean-Frédéric Vergnies, "Mieux identifier les ségrégations, étape clé pour plus d'égalité », Formation emploi [En ligne], 120 | Octobre-Décembre 2012, mis en ligne le 08 janvier 2015, consulté le 30 octobre 2020. URL : http://journals.openedition.org/formationemploi/3776 ; DOI : https://doi.org/10.4000/ formationemploi.3776 


\title{
Démasquer les ségrégations à l'œuvre
}

\author{
Jean-Frédéric Vergnies \\ Rédacteur en chef
}

L es inégalités sont d'autant moins acceptables qu'elles sont durables et cumulatives. Elles se cristallisent alors dans des ségrégations. Or comme le rappelle Philippe Lemistre dans son introduction, les ségrégations scolaires sont peu médiatisées, notamment car elles sont peu perceptibles. Pourtant, elles constituent un "phénomène puissant » d'autant plus important que ses conséquences peuvent affecter toute la vie des individus. Ce dossier identifie plusieurs facettes des ségrégations scolaires.

Noémie Olympio et Valérie Germain soulignent le poids de l'environnement socioculturel sur les trajectoires scolaires. Elles analysent comment les différents facteurs sociaux, qui peuvent se cumuler, conduisent à élargir le champ des possibles, pour certains, et à le restreindre, pour d'autres. L'espace des possibles au cours des trajectoires de formation est ici étudié à l’aune de la théorie des « capabilités » de l'économiste Amartya Sen.

Les contributions suivantes s'intéressent aux effets des territoires et des établissements de formation. Pour sa part, Danièle Trancart met à jour une accentuation des ségrégations sociales et scolaires à partir de certaines méthodes utilisées dans la mesure de la ségrégation socio-spatiale. Elle montre alors le lien entre ségrégation sociale, concurrence entre établissements et faibles performances scolaires au collège.

Loin de se cantonner au collège, les ségrégations territoriales et entre établissements existent aussi dans l'enseignement supérieur. Ces phénomènes sont illustrés par Sandrine Nicourd, Olivia Samuel et Sylvie Vilter à partir d'enquêtes réalisées sur deux universités de la région parisienne pour la filière Administration économique et sociale (AES).

Un retour aux études après la formation initiale serait-il alors une solution ? En s'appuyant sur la situation canadienne, Pierre Doray, Pierre Canisius Kamanzi, Benoît Laplante et María Constanza Street confirment que le retour aux études est influencé par la scolarité antérieure et certaines marques du passage à l'âge adulte (type d'occupation, revenu, vie en couple...). L'hypothèse de la persistance des effets des ségrégations sociales se trouve ici également confortée. 
Enfin, dernière facette analysée dans ce dossier, la massification scolaire ne semble constituer qu'un remède partiel aux ségrégations. Ainsi, à partir du cas emblématique de la Nouvelle-Calédonie, Laure Hadj, Gaël Lagadec, Gérard Lavigne et Catherine Ris retracent comment la progression du niveau de qualification en Nouvelle-Calédonie s'est accompagnée d'inégalités ethniques persistantes. Au-delà de la réflexion sur les relations entre massification de l'enseignement et " démocratisation qualitative ", cet article étudie, de manière fort originale pour la littérature académique française, les ségrégations ethniques.

Pour clore ce numéro, dans la postface, Agnès van Zanten plaide pour une plus grande homogénéisation des publics en retardant et en limitant le nombre de bifurcations possibles dans les parcours, et en s'attaquant aux processus qui concourent à ce que les voies de diversification deviennent des voies hiérarchisées reproduisant les inégalités.

Bonne lecture. 